\title{
The Swedish National Safety Promotion Program
}

\author{
Lothar Schelp, Leif Svanström
}

Injuries are a global public health problem, causing about three and a half million deaths each year. ${ }^{1}$ In Sweden, despite major advances, injury remains the most common cause of death in children, adolescents, and young adults. About 3000 people die from unintentional injuries each year in Sweden and about 160000 are hospitalised. Injuries account for 4125560 days of hospitalisation ${ }^{2}$ and are responsible for about 900000 medical consultations annually. In addition, there is the toll of intentional injuries to be considered. Each year 140 people die due to acts of violence, and each day six or seven are admitted to hospital as a consequence of assault. ${ }^{2}$ Although over the last 10 years injury mortality in Sweden has decreased by $10 \%{ }^{3}$ in 1990 the societal costs of injuries were roughly equivalent to $4 \%$ of the Swedish gross national product. ${ }^{4}$

The Swedish Health and Medical Services Act of 1983 urges the health services to become more involved, not only in disease prevention but also in safety promotion. The first 'Health for all' program covering all areas and all levels of injury prevention and safety promotion was established in $1986 . .^{5}$ In its initial phase, it focused on intersectoral cooperation and the participation of diverse governmental organisations. This report describes the further development of the program in the context of the National Institute of Public Health established in 1992. The institute's function is to promote health and prevent disease. It works at the national level by adopting strategic measures to stimulate and support public health efforts.

The National Safety Promotion Program (NSPP) at the National Institute of Public Health, is a nationwide network with many branches. It is based on 'Strategies for a safe Sweden', prepared in 1990/1 by a coordinating committee representing many authorities and organisations involved in injury prevention. The NSPP relies on intersectoral collaboration at local, county, and national level, and on cooperation between authorities, scientific institutions, and local practitioners. It requires the participation of politicians, civil servants, researchers, representatives of non-governmental organisations, and local public health workers.

Its primary objective is to create a national network with branches at all levels and in all environments. Its other objectives are:

- To develop local safety work

- To extend intersectoral collaboration at local, regional, and national levels

- To increase public awareness of injury risks and hazardous environments
- To reduce injuries with special emphasis on certain risk groups and environments

- To increase knowledge of what is being done to prevent injuries due to violence and what should be done in the future.

The program is expected to initiate and implement national strategies by:

- Monitoring and analysing the magnitude of the problem and causal patterns

- Publishing timely reports for local communities

- Developing an 'ABC of safety', comprising information on safety legislation and regulations

- Promoting the use of bicycle helmets

- Developing a 'risk hotline' to enable the general public to report environmental hazards and dangerous products

- Analysing the role of non-governmental organisations

- Promoting research, especially on injuries among the elderly

- Organising conferences, seminars, and postgraduate courses

- Monitoring current prevention projects and initiating new, local projects.

Safety promotion requires a permanent organisation and collaboration between different levels of society (central, regional, and local), between different areas of activity, and between researchers and practitioners. One issue of particular relevance is how experiments and projects can be linked to, and transformed into, long term activities. Another task of the NSPP is to provide support for safety promotion. This involves creating networks, disseminating models and examples, formulating problems, putting these problems on the agenda, and moulding public opinion.

In Sweden, many societal sectors have lengthy experience of safety promotion but there is a need for coordinated action. Thus, at the national level, two intersectoral groups form part of the network: one dealing with unintentional injuries, the other with injuries related to violence. A news bulletin with topical information is published periodically.

One of the specific features of the program is building up skills among involved personnel. There is a need for better training and education at all levels. A masters course in public health on injury epidemiology and safety promotion was created in collaboration with the Karolinska Institute. To support this, a textbook has been compiled and courses held for health inspectors, health planning officers, and students at medial faculties. There have been, and will continue to be, regular meetings with people working in the network. Training 
opportunities will be offered at the masters and doctoral levels, along with other educational activities. Five national safety promotion conferences, one every second year, have been organised so far.

The program has collaboration agreements or works closely with the Skaraborg Institute (which develops networks for local safety work), the Department of Public Health Sciences at the Karolinska Institute, and the Department of Community Medicine at the University of Linköping (which conducts research in the field of injury prevention).

Six county councils have developed countywide programs encompassing their responsibility for safety promotion and how activities are either rooted in and transmitted to their municipalities. ${ }^{6}$ These countywide programs exist in Östergötland, Jämtland, Skaraborg, Uppsala, Bohuslän, and Stockholm. Each is conducted within a variety of politicalorganisational frames. These organisational variations hinge primarily on the political organisation of the county council.

Intersectoral collaboration occurs through, among others, the county section of the Association of Municipal Authorities, the County Administrative Board, the Regional Social Insurance Office, sports associations, schools, the labour market, and non-governmental organisations. Experiences at the local level demonstrate that injury prevention can be organised in many different ways. ${ }^{6}$ Cooperation within and between municipalities and county council requires that the commitment to safety promotion activities within a county council spreads to its municipalities and that there are operating models for organisational collaboration.

Swedish experience shows that the most important step is to develop community intervention models. It is at the local level that people become involved. At this level people know a lot about hazards in their community and by getting them involved the foundations are laid for safety promotion through a democratic process.

\section{The Safe Community Program}

The Safe Community Program is part of the NSPP. The concept of a 'safe community' has been developed in collaboration with the World Health Organisation. ${ }^{7}$ Strategies for a safe community are based on the structure and organisation specific to the community to which the model is applied. The criteria for a safe community reflect the 'community intervention' approach - a method that is based on popular participation and intersectoral cooperation between all the organisations affected. A national, Nordic, and global network of safe communities is being constructed. Research and exchange of knowledge and experience between different communities is an important part of this work.

Five Swedish municipalities have become members of the International Safe Communities Network: Lidköping, Motala, Falköping, Falun, and Krokom. These municipalities participate in the institute's coordinating model and spread the experience gained by other local communities. Together they are building a network that comprises all municipalities actively committed to creating a safe and secure society. For the prevention of violence and self inflicted injuries, both new areas for action, the development of specific local strategies are clearly necessary.

\section{Injury surveillance system}

A national injury register, which includes other data sets such as records of deaths, hospitalisations, and outpatient treatment, is being developed at the National Board of Health and Welfare's Centre for Epidemiology and Social Analysis (EpC). It is necessary to construct a surveillance system that ensures all interested parties ready access to current data of the best possible quality. A network has been built comprising persons in county councils with responsibility for epidemiology and injury statistics and those engaged in injury prevention and safety promotion. A handbook for monitoring, a manual for classification, and methods for surveillance, have been developed. ${ }^{8}$ At present, about 150 hospitals and health centres are engaged in injury reporting. In parallel with this, steps are being taken to ensure that information on injuries (intentional and unintentional) are included in the primary care register being established by the EpC. The NSPP has published a Swedish mortality and morbidity atlas showing regional and local incidence rates for injuries in general, unintentional injuries, violence, and suicide. ${ }^{9}$

\section{The bicycle helmet initiative}

The number of cyclists killed is about one tenth the total number of people killed in traffic. Between one third and one half of all traffic injuries necessitating hospital care are related to bicycling ${ }^{10}$ and about one third of all injured cyclist sustains an injury to the head. The average use of helmets is $5 \%$ for adults, $20 \%$ for teenagers, and $35 \%$ for children. The goal of this initiative is thus to increase helmet use. ${ }^{11}$ By the year 2000 the objective is $80 \%$ helmet use among children, $75 \%$ among those aged 13 to 64 years, and $85 \%$ among those 65 years and older.

\section{Risk information hotline}

A nationwide risk information hotline is being developed in collaboration between the National Institute of Public Health, Jämtland County Council, the Municipality of Östersund, and SOS-Alarm. This hotline has a special telephone number on which no charges are made. Weekly reports on the risk of playground, traffic, recreational, and residential injuries and on dangerous products, are distributed to municipal departments. If an acute hazard is reported, it is dealt with immediately.

\section{The ABC of safety}

A collaborative group of relevant authorities and representatives of the local community 
have developed the 'ABC of safety'. This is a source of information on Swedish laws and regulations aimed at preventing personal injuries, particularly at local level.

\section{Non-governmental organisations}

A survey of non-governmental organisation's interest in injury prevention at central and local level, covering both intentional and unintentional injuries, has been conducted. Experience so far gained from the program can be used in this context, as can a municipality's or county council's experience of collaboration.

\section{Research}

Research into safety promotion is still sparse. Much of the effort should be directed towards initiating and supporting research in areas that are judged to be particularly relevant to the program. Our theoretical foundation needs to be improved. We need to know more about why accidents and injuries occur. To this end two posts have recently been created at the Karolinska Institute for the development of methods and models for local injury prevention and methods for evaluating local safety work. In collaboration with the University of Linköping, research on the effect of intervention programs and their cost effectiveness has been embarked upon. Further, a study that highlights determinants and intervention needs with regard to injuries at school has been initiated in collaboration with the National Institute of Occupational Health.

\section{Conclusions}

The major differences between countries and areas in injury rates can partly be explained by differences in social structure, political organisation, and safety legislation. An important strategy of the NSPP is to reach out to broad groups of people who can contribute in various ways to safety promotion. Depending on the nature and seriousness of the risk, simultaneous action can be taken to eliminate risks through information, education, surveillance, and improvement of the environment. This necessitates a holistic approach that embraces all ages and environments and that requires collaboration between interested parties. In certain cases, national legislation or regulations will be needed to eliminate injury hazards.

1 World Health Organisation. Handle life with care. Information Kit. World Health Day 7 April 1993. Geneva: WHO, 1993.

2 Swedish National Institute of Public Health. Strategies for success. Stockholm: Swedish National Institute of Public Health, 1994 (report 1994: 4).

3 Swedish National Board of Health and Welfare. Public health report. Stockholm: Swedish National Board of Health and Weport. Stockho, 1994.

4 Lindqvist $\mathrm{K}$, Brodin $\mathrm{H}$. One-year economic consequences of accidents in a Swedish municipality. Accid Anal Prev accidents in a $\mathrm{Sw}$

5 Svanström L, Schelp L, Skjönberg G. The establishment of a national safety promotion programme for prevention of accidents and injuries - the first Swedish 'health for all' programme - implemented in practice. International fournal for Health Promotion 1989; 4: 343-7.

6 Andersson R. Community safety at local, regional, and national levels. International fournal for Consumer Safety 1995; 2: 61-70.

7 Svanström $\mathrm{L}$. What is a safe community and how can we plan a community safety program? Sundbyberg: Karolinska Institute, Department of International Health and Social
Medicine, 1993 (report No 289).

8 Swedish National Board of Health and Welfare. Classification of unintentional Injuries 1989. Stockholm: Swedish National Board of Health and Welfare, 1989. (English version.)

9 Swedish National Institute of Public Health. Injury mortality and morbidity atlas. Stockholm: Swedish National tality and morbidity atlas. Stockholm: Swedish Na
Institute of Public Health, 1995 (report 1994: 28).

10 Lind MG, Wolin S. Bicycle accidents. Acta Chir Scand 1986; suppl 531.

11 Ekman R, Schelp L, Svanström L, Welander G. The Swedish bicycle helmet initiative. Stockholm: Karolinska Institute, Department of Social Medicine, 1991 (report 271). 